medRxiv preprint doi: https://doi.org/10.1101/2020.05.01.20087288; this version posted May 6, 2020. The copyright holder for this preprint (which was not certified by peer review) is the author/funder, who has granted medRxiv a license to display the preprint in perpetuity. It is made available under a CC-BY-NC-ND 4.0 International license.

\title{
Impact of campaign-style delivery of routine vaccines during Intensified Mission Indradhanush in India: a controlled interrupted time-series analysis
}

Version: 30 April 2020

Emma Clarke-Deelder, MPhil1; Christian Suharlim, MD MPH4,5; Susmita Chatterjee, PhD3,6; Logan Brenzel, $\mathrm{PhD}_{2}$; Arindam Ray2, Jessica Cohen, PhD1; Margaret McConnell, PhD1; Stephen $\mathrm{C}$ Resch, PhD4; Nicolas A Menzies, $\mathrm{PhD}_{1,4}$

Affiliations: 1Harvard T. H. Chan School of Public Health, Department of Global Health and Population; 2Bill \& Melinda Gates Foundation; ${ }_{3}$ George Institute for Global Health; 4 Harvard T. H. Chan School of Public Health, Center for Health Decision Science; 5 Management Sciences for Health; 6 University of New South Wales

Correspondence to: Emma Clarke-Deelder, Department of Global Health and Population, Harvard T. H. Chan School of Public Health, 665 Huntington Avenue, Boston, MA, 02115.

Email: emmaclarke@g.harvard.edu 
medRxiv preprint doi: https://doi.org/10.1101/2020.05.01.20087288; this version posted May 6, 2020. The copyright holder for this preprint (which was not certified by peer review) is the author/funder, who has granted medRxiv a license to display the preprint in perpetuity.

It is made available under a CC-BY-NC-ND 4.0 International license .

\begin{abstract}
Introduction: The world is not on track to achieve the goals for immunization coverage and equity described by the World Health Organization's Global Vaccine Action Plan. In India, only $62 \%$ of children had received a full course of basic vaccines in 2016 . We evaluated the Intensified Mission Indradhanush (IMI), a campaign-style intervention to increase routine immunization coverage and equity in India, implemented in 2017-2018.
\end{abstract}

Methods: We conducted a comparative interrupted time-series analysis using monthly districtlevel data on vaccine doses delivered, comparing districts participating and not participating in IMI. We estimated the impact of IMI on coverage and under-coverage (defined as the proportion of children who were unvaccinated) during the four-month implementation period and in subsequent months.

Findings: During implementation, IMI increased delivery of thirteen infant vaccines by between 1.6\% (95\% CI: $-6.4,10.2 \%)$ and 13.8\% (3.0\%, 25.7\%). We did not find evidence of a sustained effect during the 8 months after implementation ended. Over the 12 months from the beginning of implementation, IMI reduced under-coverage of childhood vaccination by between $3.9 \%$ ($6.9 \%, 13.7 \%)$ and $35.7 \%(-7.5 \%, 77.4 \%)$. The largest estimated effects were for the first doses of vaccines against diptheria-tetanus-pertussis and polio.

Interpretation: IMI had a substantial impact on infant immunization delivery during implementation, but this effect waned after implementation ended. Our findings suggest that campaign-style interventions can increase routine infant immunization coverage and reach formerly unreached children in the shorter term, but other approaches may be needed for sustained coverage improvements.

Funding: Bill \& Melinda Gates Foundation. 
medRxiv preprint doi: https://doi.org/10.1101/2020.05.01.20087288; this version posted May 6, 2020. The copyright holder for this preprint (which was not certified by peer review) is the author/funder, who has granted medRxiv a license to display the preprint in perpetuity. It is made available under a CC-BY-NC-ND 4.0 International license .

\section{Introduction}

Despite significant investments in improving immunization coverage, the world is not on track to achieve the goals set by the World Health Organization (WHO)'s Global Vaccine Action Plan for 2011-2020 (1). Global coverage of the third dose of diphtheria-tetanus-pertussis (DTP) vaccine, a measure of routine immunization system performance, stagnated between 2011 and 2018 (2). In India in 2016, only $62 \%$ of children received a full course of basic vaccines, and state-level coverage ranged from $35 \%$ to $91 \%$ (4).

There is little rigorous evidence about how to effectively improve routine immunization coverage $(5,6)$. One widely-applied strategy - "periodic intensification of routine immunization" - adapts techniques from mass immunization campaigns and applies them to the delivery of routine vaccines (7)(8). Mass immunization campaigns have been reported to achieve high vaccine coverage (9) of a single or small number of vaccines, but there is little robust evidence on the effectiveness of campaign-like approaches for delivering the full schedule of routine vaccines. While campaign-like approaches can reach many people, some fraction of these individuals may have been reached by routine services anyway. Delivery volumes reported by campaigns may therefore overestimate the net change in coverage.

In 2017-2018, the Government of India implemented a nationwide effort to improve routine immunization coverage and equity, via a campaign-like initiative called Intensified Mission Indradhanush (IMI). IMI was designed to (i) increase coverage of routine vaccines for infants under two and pregnant women in selected low-performing districts, and (ii) sustain these gains by raising public awareness of routine immunization and strengthening routine planning. IMI was one of the largest ever applications of the "periodic intensification of routine immunization" strategy.

In this study, we conducted a quasi-experimental evaluation of IMI. Using a controlled interrupted time-series approach, we estimated the impact of IMI on vaccine delivery, coverage, and under-coverage for 15 vaccines in the routine immunization schedule.

\section{Methods}

\section{Study setting}

India's immunization program serves a target population of approximately 27 million newborns and 30 million pregnant women annually (10). Vaccinations are provided through public health facilities and community-based outreach sessions, with an estimated nine million immunization sessions held annually (11). The routine schedule includes 25 childhood vaccines and two vaccines for pregnant women (Table 1). Vaccines are administered according to a schedule by age, but some vaccines can be administered late (12).

Many children and pregnant women do not receive the full schedule of vaccines. Reasons for under-immunization include low awareness (13), inaccessibility of vaccination services (13), anti-vaccine sentiment (14), and under-staffing of health facilities (15). In recent years, in an effort to increase coverage, the Government of India implemented a series of campaign-like 
medRxiv preprint doi: https://doi.org/10.1101/2020.05.01.20087288; this version posted May 6, 2020. The copyright holder for this preprint (which was not certified by peer review) is the author/funder, who has granted medRxiv a license to display the preprint in perpetuity. It is made available under a CC-BY-NC-ND 4.0 International license .

interventions called Mission Indradhanush (MI). These interventions fell short of their objectives, leading to the design and implementation of IMI (10).

\section{Intervention}

The Government of India implemented IMI from October 2017 through January 2018 as part of the Pro-Active Governance and Timely Implementation (PRAGATI) initiative, a set of programs prioritized by the office of the Prime Minister. Districts with weak immunization performance ( $<70 \%$ estimated DTP3 coverage, or $>13,000$ children missing DTP3 in the previous year) were included, and additional districts added based on requests from states (10). In total 187 districts and urban areas were included.

IMI implementation began with door-to-door surveys to identify under-immunized children. District-level micro-plans were then developed to determine the location of IMI vaccination sites and ensure supply availability. Site selection focused on areas with low coverage, with particular emphasis on urban slums and nomadic populations. Social mobilization campaigns were conducted to raise awareness. Finally, immunization sessions were conducted for seven consecutive days per month during implementation. Sessions were conducted by auxiliary nursemidwives (ANMs), who left their postings in periphery health facilities to deliver vaccines and other health services at the selected locations.

\section{Data sources}

Outcome data at the district-month level were extracted from India's Health Management Information System (HMIS), which compiles service delivery data reported by health facilities. We used data on vaccine doses delivered from October 2015 through September 2018, encompassing two years before the start of IMI and one year after. We used data on thirteen vaccines for children and two for pregnant women: Hepatitis B birth dose (HepB0), BacillusCalmette-Guérin (BCG), four doses of diptheria, tetanus, and pertussis-containing vaccines (DTP1, DTP2, DTP3, and DTP booster (DTPb)), five doses of oral polio vaccine (OPV0, OPV1, OPV2, OPV3, and OPV booster (OPVb)), two doses of measles-containing vaccines (M1 and M2); and the first and second dose (or booster) of tetanus toxoid vaccine (TT1 and TT2) for pregnant women. We also used HMIS data on the number of immunization sessions held per district-month. We excluded the Japanese encephalitis vaccine because it is only delivered in endemic areas. We excluded rotavirus, pneumococcal, and inactivated polio vaccines because they were recently introduced and not available for the full study period. We excluded vaccines for children over age two (a second DTP booster and tetanus toxoid), because IMI primarily targeted children under two and pregnant women. While we included HepB0 and OPV0, we did not expect large effects for these vaccines because the catch-up period is limited to 24 hours and 15 days post-birth, respectively.

To identify districts included in IMI we used publicly available documents from the Indian Universal Immunization Program (16). We also extracted covariate data from India's 2015-2016 Demographic and Health Surveys (DHS), summarized at the district level (4). This included vaccine coverage and urbanization (percent of children under five living in an urban area). Finally, we used World Bank estimates of India's 2017 population size, fertility rate, and 
medRxiv preprint doi: https://doi.org/10.1101/2020.05.01.20087288; this version posted May 6, 2020. The copyright holder for this preprint (which was not certified by peer review) is the author/funder, who has granted medRxiv a license to display the preprint in perpetuity. It is made available under a CC-BY-NC-ND 4.0 International license .

neonatal mortality rate to generate estimates of the target population size for different vaccines (17).

\section{Sample}

The study sample included all districts in India meeting two criteria: (1) they had available HMIS data for the full study period, and (2) these data could be merged with DHS data. We omitted 8 of 187 IMI districts and 110 of 549 control districts that did not meet these criteria(Table S1).

\section{Statistical analysis}

We conducted a comparative interrupted time-series (CITS) analysis. This quasi-experimental method accounts for time trends that would have occurred in the absence of the intervention, and for exogenous shocks that could have affected the outcome trend in both the treatment and control group $(18,19)$. Our analysis assumed that, in the absence of IMI, deviations from past trends in vaccine delivery would have been the same for treated and control districts.

We modelled time trends in district-level vaccination volume (doses delivered) using generalized linear models with quasi-Poisson distributed outcomes and a log link, in order to appropriately model count data with over-dispersion $(20,21)$. We included dummy variables to model intercept changes on 1 October 2017 (the start of IMI), 1 February 2018, and 1 June 2018. We therefore measured the impact of IMI on vaccine delivery during the four-month implementation period and two four-month post-implementation periods. By including two post-implementation periods, we assessed whether immunization delivery volumes returned to or dipped below their pre-intervention levels after IMI implementation ended. From this analysis we estimated the impact of IMI during the 4-month implementation period, as well as the net impact over the full year following the beginning of implementation.

We assessed whether IMI was more effective in districts with lower coverage or higher levels of urbanization (because these were focus areas of the program) by including interaction terms in our regression models. We also included calendar month fixed effects to adjust for seasonality, and district fixed effects to absorb variation in the initial level of vaccination volume. We used Newey-West standard errors to adjust for potential serial autocorrelation (22).

Because the treatment effect in CITS is captured by multiple coefficients, it is common practice to generate interpretable results by making predictions from fitted models (23). Following this practice, we estimated vaccination volume in the treated districts if IMI had not occurred and compared this to the observed vaccination volume under IMI. We estimated the incremental vaccination volume attributable to IMI by projecting model results to the full set of treated districts with covariates fixed to their true values. To describe how the estimated treatment effect varied by district characteristics, we generated treated effect estimates from models fixing the values of covariates to their 25 th and 75 th percentiles in the treated districts. We estimated equaltailed $95 \%$ confidence intervals $(95 \% \mathrm{CI})$ for all effects (24). 
medRxiv preprint doi: https://doi.org/10.1101/2020.05.01.20087288; this version posted May 6, 2020. The copyright holder for this preprint (which was not certified by peer review) is the author/funder, who has granted medRxiv a license to display the preprint in perpetuity. It is made available under a CC-BY-NC-ND 4.0 International license .

To estimate the impact of IMI on coverage in the treated districts, we divided our estimates of incremental doses delivered by estimates of the target population size. We estimated the target population size for HepB, OPV0, BCG, TT1, and TT2 as the number of live births in 2017, calculated as fertility rate multiplied by population size. We estimated the target population size for DTP1-3, OPV1-3, and M1-2 as the number of surviving infants in 2017, calculated by multiplying live births by one minus the neonatal mortality rate. To estimate the impact of IMI on under-coverage (percent reduction in unvaccinated children) we divided our estimates of incremental doses delivered by estimates of the number of children who would not have been reached if IMI had not occurred. We estimated the number of unreached children by multiplying the target population size by one minus coverage in 2016 .

To examine mechanisms for the treatment effect, we measured the impact of IMI on the number of immunization sessions held (including both routine and IMI sessions), and the ratio of incremental doses delivered to incremental immunization sessions held.

Sensitivity analysis

We examined the robustness of our results to different model specifications including single interrupted time-series analysis, a matched analysis using a subset of the study sample (coarsened exact matching on geographic location, baseline coverage, urbanization level, and participation in the earlier MI program), and restriction of the comparison group to untreated districts that do not share borders with treated districts.

Supplementary Appendix A provides detailed analytic methods.

\section{Role of the funding source}

Employees of the funder (LB and AR) participated as scientific collaborators. The corresponding author made the final decision to submit the paper for publication.

\section{Results}

\section{Impact of IMI on vaccination volume}

During the four-month implementation period, IMI had a positive estimated impact on delivery volume for all infant vaccines in the study (Figures 1 and 2). During implementation, IMI increased infant vaccination volume by between $1.6 \%$ (HepB0; 95\% CI: -6.4, 10.2) and 13.8 $(\mathrm{DTPb} ; 3.0,25.7)$, with a median of $10.6 \%$. There was no statistically discernable impact of IMI on the delivery of vaccines for pregnant women (median $-0.9 \%$ ).

The estimated effect of IMI waned after implementation ended. With the exception of TT2, there was no statistically discernable impact of IMI on delivery of any antigen during the period from February to May 2018 or the period from June to September 2018. Point estimates for all estimated effects were modestly negative from February to May 2018, with the exception of OPV0, DTP1, and OPV1 (median value -1.8\%). Point estimates for all estimated effects were positive from June 
medRxiv preprint doi: https://doi.org/10.1101/2020.05.01.20087288; this version posted May 6, 2020. The copyright holder for this preprint (which was not certified by peer review) is the author/funder, who has granted medRxiv a license to display the preprint in perpetuity. It is made available under a CC-BY-NC-ND 4.0 International license .

to September 2018, with the exception of OPVb, but none were statistically significant (median value $2.7 \%$ ).

Over the full year from the beginning of implementation, we estimated positive impacts of IMI on the number of doses delivered of all infant vaccines and TT1, and a negative impact on doses delivered of TT2 (Table 3). None of these estimates were statistically significant. We estimated that IMI reached between 148,000 (95\% CI: -263,000; 521,000) and 491,000 (-100,000; $1,033,000)$ additional infants with each infant vaccine in the study. We estimated that IMI reached $6,000(-95 \% \mathrm{CI}: 393,000 ; 398,000)$ additional pregnant women with TT1 and -102,000 $(-441,000 ; 215,000)$ additional pregnant women with TT2.

\section{Impact of IMI on coverage and under-coverage}

Based on these changes in vaccination volume, we estimated percentage point improvements in coverage ranging from $-1.2(-5.2 ; 2.5)$ for TT2 to $5.9(-1.2 ; 12.5)$ for DTP1, assessed over the full year following the beginning of implementation.

We estimated that IMI reduced the number of unvaccinated children by between $3.9 \%$ (95\% CI: $-6.9,13.7)$ for HepB0 and $35.7 \%(-7.4 ; 77.4)$ for DTP1, and reduced the number of unvaccinated pregnant women by $0.7 \%$ for TT1 $(-47.2 ; 49.9)$ and $-6.5 \%$ for TT2 $(-27.8 ; 13.5)$.

\section{Effects of urbanization and baseline coverage}

We found small and inconsistent results for the impact of urbanicity and baseline DTP3 coverage on IMI impact estimates. The estimated impact of IMI on coverage was higher in more urbanized areas for four of the vaccines evaluated, and lower for eleven vaccines. For baseline DTP3 coverage, the estimated impact of IMI was higher in districts with higher baseline coverage for nine of the vaccines evaluated, and lower for five vaccines. Detailed results are provided in Table S2.

\section{Immunization sessions held, and doses per session}

During implementation, IMI was estimated to have increased the number of immunization sessions held per treated district by $11.2 \%$ (95\% CI: 3.7; 19.4). For the two subsequent fourmonth periods the number of immunization sessions was estimated to be lower than in the absence of IMI, 7.7\% (95\% CI: -1.4; 15.9) and 6.1\% (95\% CI: -4.4; 15.5) lower, respectively. Assessed over the full year period, IMI was estimated to have produced minimal changes in the number of immunization sessions (decrease of 61,000 (95\% CI: -325,000; 475,000).

During IMI implementation, the ratio of incremental infant vaccine doses to incremental immunization sessions held ranged from 0.1 (95\% CI: -0.9, 0.9) doses of HepB0 per session to $2.9(1.0 ; 6.2)$ doses of DTP per session, and for maternal vaccines the ratio was $-0.6(-8.7,6.2)$ doses per session of TT1 and $-0.2(-1.3,0.8)$ doses of TT2.

Sensitivity analyses 
medRxiv preprint doi: https://doi.org/10.1101/2020.05.01.20087288; this version posted May 6, 2020. The copyright holder for this preprint (which was not certified by peer review) is the author/funder, who has granted medRxiv a license to display the preprint in perpetuity. It is made available under a CC-BY-NC-ND 4.0 International license .

We found qualitatively similar results across the eight model specifications we tested, with some variation in point estimates (Figure S6). Detailed results from the sensitivity analyses are included in the Supplementary Appendix (Tables S6-S12).

\section{Discussion}

IMI represents one of the largest efforts to improve routine immunization coverage using campaign methods that has ever been attempted. The focus of IMI was to reach children and pregnant women previously unreached by the vaccination program, to increase coverage and improve equity. Evidence on the effectiveness of this approach can be used to guide future investments in similar types of approaches in India and elsewhere.

We found that IMI substantially increased delivery for thirteen infant vaccines, but not for two vaccines for pregnant women. Assessed over a full year, IMI increased infant vaccine coverage by between $1.6(-3.5,5.9)$ and $4.8(-2.7,11.7)$ percentage points across different vaccines, reaching between $3.9 \%(-6.9,13.7)$ and $35.7 \%(-7.5,77.4)$ of children who otherwise would not have been reached. The largest estimated effects were for DTP1 and OPV1, which suggests that IMI was able to reach previously unvaccinated ("zero dose") children. The smallest effects were for HepB0 and OPV0; this was expected because these vaccines are only administered up to 24 hours and 15 days after birth, respectively.

Previous RCTs that evaluated interventions similar to IMI, involving immunization outreach at sites closer to communities and social mobilization to increase awareness of vaccination services, found larger effects on coverage $(5,25)$. However, interventions that are successful in the context of an RCT do not always have the same effect when implemented at scale. Outside of a trial setting, the intervention may not be as tailored to the population's needs, and adherence to program design may not be as consistent. The smaller effect of IMI could also be due in part to low efficiency: while the number of immunization sessions significantly increased during IMI implementation, the efficiency of these sessions (measured as doses delivered per session) was low. We estimated that for infant vaccines, between 0.9 and 2.2 additional doses were delivered per additional session held during the implementation period. This could be because demand was low or because the sessions were not well planned.

An earlier evaluation of IMI also estimated larger (though directionally similar) effects (10). The earlier study used data from household surveys, which have several advantages over the HMIS data used in our study, and can provide direct estimates of coverage. However, this prior study relied on baseline data from two years before the start of IMI and was not able to control for time trends in vaccine delivery that would have occurred in the absence of IMI. This approach would lead to overestimates of the impact of IMI if there were secular improvements in coverage over the two-year period not attributable to IMI. In addition, the prior study did not assess the potential for a rebound effect, whereby vaccination delivery volume decreased in the months following IMI implementation. Our results suggest that evaluations of campaign-style interventions should include a sufficiently long post-period to account for the possibility of rebound after implementation. 
While one of the objectives of the IMI program was to have a sustained effect (by raising awareness of the routine immunization program and improving routine planning), we did not find evidence for a sustained effect during the 8-months after IMI implementation ended. During the first four months after implementation, we found a small rebound effect: vaccination volume decreased, though not by a statistically significant amount. During the subsequent four months, vaccination volume increased again, though again not by a statistically significant amount. The presence of a rebound directly after implementation suggests that, for some children, IMI may have improved vaccination timeliness. Reducing delays in immunization can improve health outcomes by to reducing exposed time, though this was not IMI's objective (26). The lack of evidence for a sustained effect on coverage may be because IMI did not address long-term health system gaps such as human resource constraints and last-mile supply chain challenges. The reasons for lack of sustained impact need further study to inform the design of future interventions.

Although IMI had a special focus on reaching children in urban slum areas and in the poorest performing districts, we did not find substantial variation in treatment effect size by urbanization or baseline coverage (16). Differences in treatment effect size by urbanization and baseline coverage were mostly small and statistically insignificant. This could be driven by our use of district-level data, as it is possible that there was more meaningful variation by urbanization and coverage within districts. It is important to note that all districts included in IMI were selected for weak immunization performance, so, by increasing coverage in the treated districts, IMI had a meaningful impact on geographic equity in India even if the treatment effect size was similar across treated districts.

Our study has several limitations. First, because HMIS data are noisy, our estimates have low precision. We used a quasi-Poisson distribution to accurately estimate uncertainty in the presence of over-dispersion in HMIS data. Second, routinely collected data, such as HMIS data, can be subject to over- or under-reporting. Misreporting that was random, consistent over time, or followed similar trends in treated and untreated districts would not bias our study findings. However, our findings could be biased if IMI influenced reporting practices. While we cannot know for sure, we do not believe this happened: IMI doses were reported into the HMIS system the same way as other doses, and reward payments for health workers did not change during IMI. Third, our main analysis used data on vaccination volume rather than direct measures of coverage. We therefore used auxiliary data sources to calculate target population size for estimating impacts on coverage and under-coverage. The accuracy of our impact estimates for coverage and under-coverage relies on the accuracy of these auxiliary data. Fourth, our causal inference approach relied on the untestable assumption that vaccine delivery trends would have changed the same way in treated and untreated districts if IMI had not occurred. We tested the robustness of our results to a wide range of model specifications and comparison groups, and found qualitatively similar results. Fifth, there were changes in the delivery of the measles vaccine in India that coincided with the study period. As a result, our estimates of the impact of IMI on delivery of M1 and M2 may be less reliable than our estimates for other vaccines. Sixth, our analysis could be strengthened through the use of data on vaccine supply stock and flow, as collected in the electronic vaccine intelligence network (eVIN), but we did not have access to these data. Finally, we did not evaluate the impact of IMI on childhood vaccines delivered after 
medRxiv preprint doi: https://doi.org/10.1101/2020.05.01.20087288; this version posted May 6, 2020. The copyright holder for this preprint

(which was not certified by peer review) is the author/funder, who has granted medRxiv a license to display the preprint in perpetuity.

It is made available under a CC-BY-NC-ND 4.0 International license.

two years, because the target population was under two years, but it is possible that IMI also had an impact on vaccine delivery to the older age group.

\section{Conclusions}

IMI was a major effort to improve immunization coverage in India. We estimate that it had a considerable impact on infant vaccine coverage during implementation, and minimal impacts after this period. "Periodic intensification of routine immunization" may be an effective strategy for reaching zero dose children, increasing routine immunization coverage, and improving equity, but may need to be followed-up with strong routine services to have long-lasting impact. Further work is needed to understand the sustainability and cost-effectiveness of this approach compared with other methods for increasing coverage, particularly for the unreached populations. 


\section{Tables and figures}

Table 1: National Immunization Schedule for Children and Pregnant Women in India

\begin{tabular}{|c|c|c|}
\hline Time point in schedule & Vaccine & Upper age limit \\
\hline Birth & $\mathrm{BCG}$ & Up to 1 year \\
\hline Birth & OPV0 & Up to 15 days after birth \\
\hline Birth & HepB0 & Up to 24 hours after birth \\
\hline 6 weeks & Penta 1 (containing DTP1) & Up to 1 year \\
\hline 6 weeks & OPV1 & Up to 5 years \\
\hline 6 weeks & IPV1 & Up to 1 year \\
\hline 6 weeks & Rota1 & Up to 1 year \\
\hline 6 weeks & PCV1 & Up to 1 year \\
\hline 10 weeks & Penta 2 (containing DTP2) & $\begin{array}{l}\text { Any age (as long as first dose is given by } \\
1 \text { year) }\end{array}$ \\
\hline 10 weeks & OPV2 & Up to 5 years \\
\hline 10 weeks & Rota2 & $\begin{array}{l}\text { Any age (as long as first dose is given by } \\
1 \text { year) }\end{array}$ \\
\hline 10 weeks & PCV2 & $\begin{array}{l}\text { Any age (as long as first dose is given by } \\
1 \text { year) }\end{array}$ \\
\hline 14 weeks & Penta 3 (containing DTP3) & $\begin{array}{l}\text { Any age (as long as first dose is given by } \\
1 \text { year) }\end{array}$ \\
\hline 14 weeks & OPV3 & Up to 5 years \\
\hline 14 weeks & IPV2 & $\begin{array}{l}\text { Any age (as long as first dose is given by } \\
1 \text { year) }\end{array}$ \\
\hline 14 weeks & Rota3 & $\begin{array}{l}\text { Any age (as long as first dose is given by } \\
1 \text { year) }\end{array}$ \\
\hline 14 weeks & PCV3 & $\begin{array}{l}\text { Any age (as long as first dose is given by } \\
1 \text { year) }\end{array}$ \\
\hline 9 months & JE1 & Up to 15 years \\
\hline 9 months & M1 & Up to 5 years \\
\hline 16 months & DTP-b & Up to 7 years \\
\hline 16 months & M2 & Up to 5 years \\
\hline 16 months & OPV-b & Up to 5 years \\
\hline 16 months & JE2 & Up to 15 years \\
\hline $5-6$ years & DTP-b2 & Up to 7 years \\
\hline 10 years & TT & Any age \\
\hline As soon as pregnancy is confirmed & TT1 & During labor \\
\hline $\begin{array}{l}\text { During pregnancy, four weeks after } \\
\text { TT1 }\end{array}$ & TT2 & During labor \\
\hline $\begin{array}{l}\text { During pregnancy, if received } 2 \text { TT } \\
\text { doses in a pregnancy within the past } \\
\text { three years }\end{array}$ & $\mathrm{TTb}$ & During labor \\
\hline
\end{tabular}

Notes: Table shows the schedule of vaccines provided for free by India's national immunization program to infants (16 months and under) and pregnant women. The vaccines provided include: Bacillus Calmette-Guérin vaccine (BCG), oral polio vaccine (OPV), Hepatitis B vaccine (HepB), pentavalent vaccine (Penta), oral polio vaccine (OPV), rotavirus vaccine (Rota), pneumococcal conjugate vaccine (PCV), Japanese Encephalitis vaccine (JE), measles vaccine (M), and tetanus toxoid vaccine (TT). The number next to the vaccine indicates the dose number in the vaccination schedule. The letter " $b$ " indicates a booster shot. The pentavalent vaccine contains protection against diptheria, tetanus, pertussis, Haemophilus Influenzae B, and Hepatitis B. It replaced three doses of the diptheriatetanus-pertussis (DTP1, DTP2, and DTP3) vaccine in India's immunization schedule in 2011, though DTP was still used in some areas at the beginning of the study period. 
medRxiv preprint doi: https://doi.org/10.1101/2020.05.01.20087288; this version posted May 6, 2020. The copyright holder for this preprint (which was not certified by peer review) is the author/funder, who has granted medRxiv a license to display the preprint in perpetuity. It is made available under a CC-BY-NC-ND 4.0 International license .

Figure 1: Time trends in vaccination volume in treated and untreated districts, 2 years before and 1 year after the start of IMI implementation

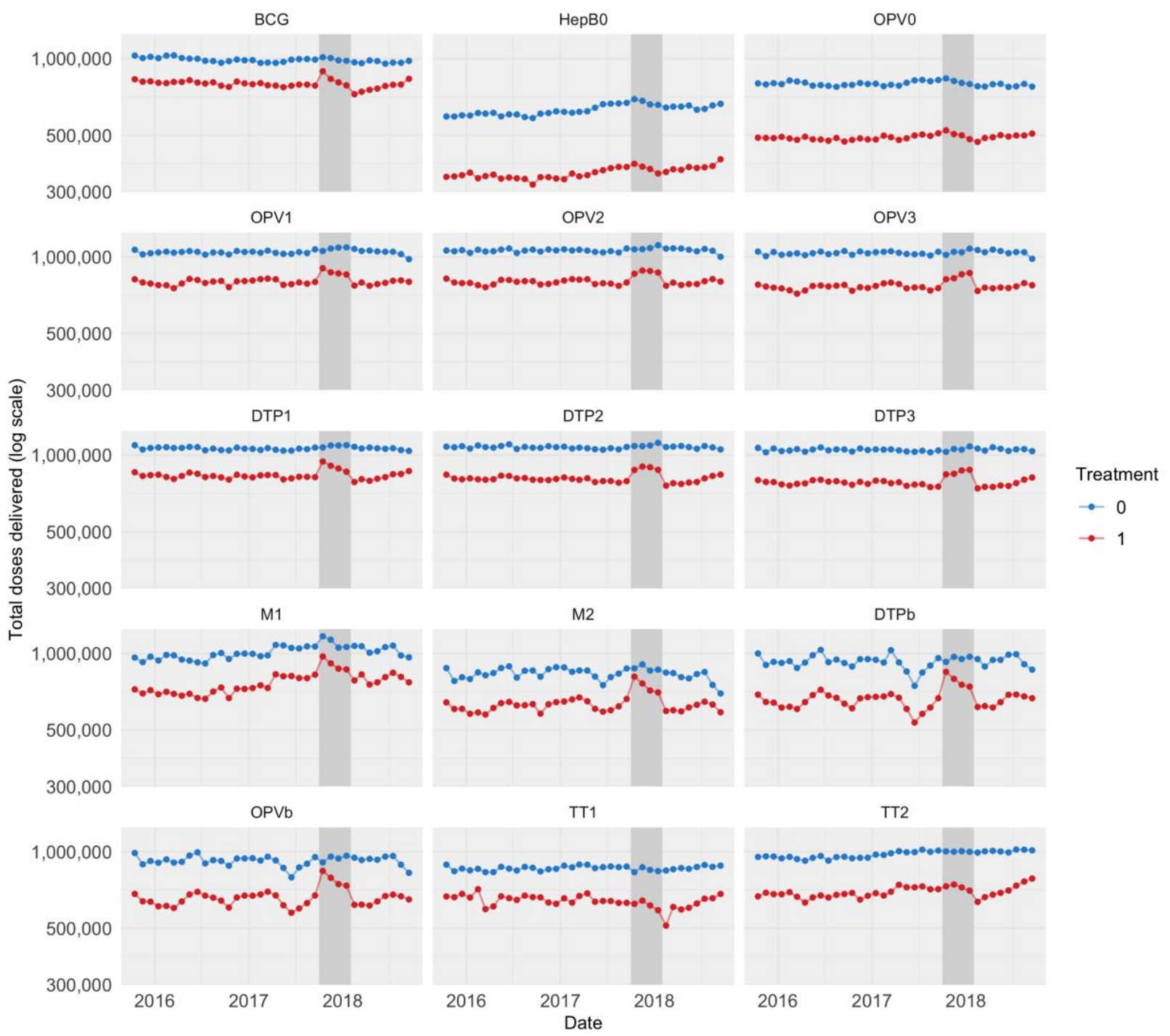

Notes: This figure shows time trends in total vaccine doses delivered in treated (red) and untreated (blue) districts in the sample. Trends are shown for the Bacillus Calmette-Guérin (BCG) vaccine, the birth dose of the Hepatitis B vaccine (HepB0), four doses of Diptheria-Tetanus-Pertussis-containing vaccine (DTP) (delivered as part of the pentavalent vaccine in recent years), five doses of the oral polio vaccine (OPV), and two doses of tetanus toxoid vaccine (TT). All vaccines shown are given to infants, apart from the tetanus toxoid vaccine, which is given to pregnant women. The dark gray bar indicates the 4-month period of IMI implementation, from October 2017 through January 2018. The 8-month period to the right of the dark gray bar is the "post-implementation" period, which is included in our analyses of the impact of IMI over a 1-year period. Raw counts of doses delivered were adjusted for seasonality by subtracting calendar month fixed effects estimated using linear regression models. 
medRxiv preprint doi: https://doi.org/10.1101/2020.05.01.20087288; this version posted May 6, 2020. The copyright holder for this preprint (which was not certified by peer review) is the author/funder, who has granted medRxiv a license to display the preprint in perpetuity.

It is made available under a CC-BY-NC-ND 4.0 International license .

Figure 2: Regression results: percent change in doses delivered in treated districts during three four-month periods

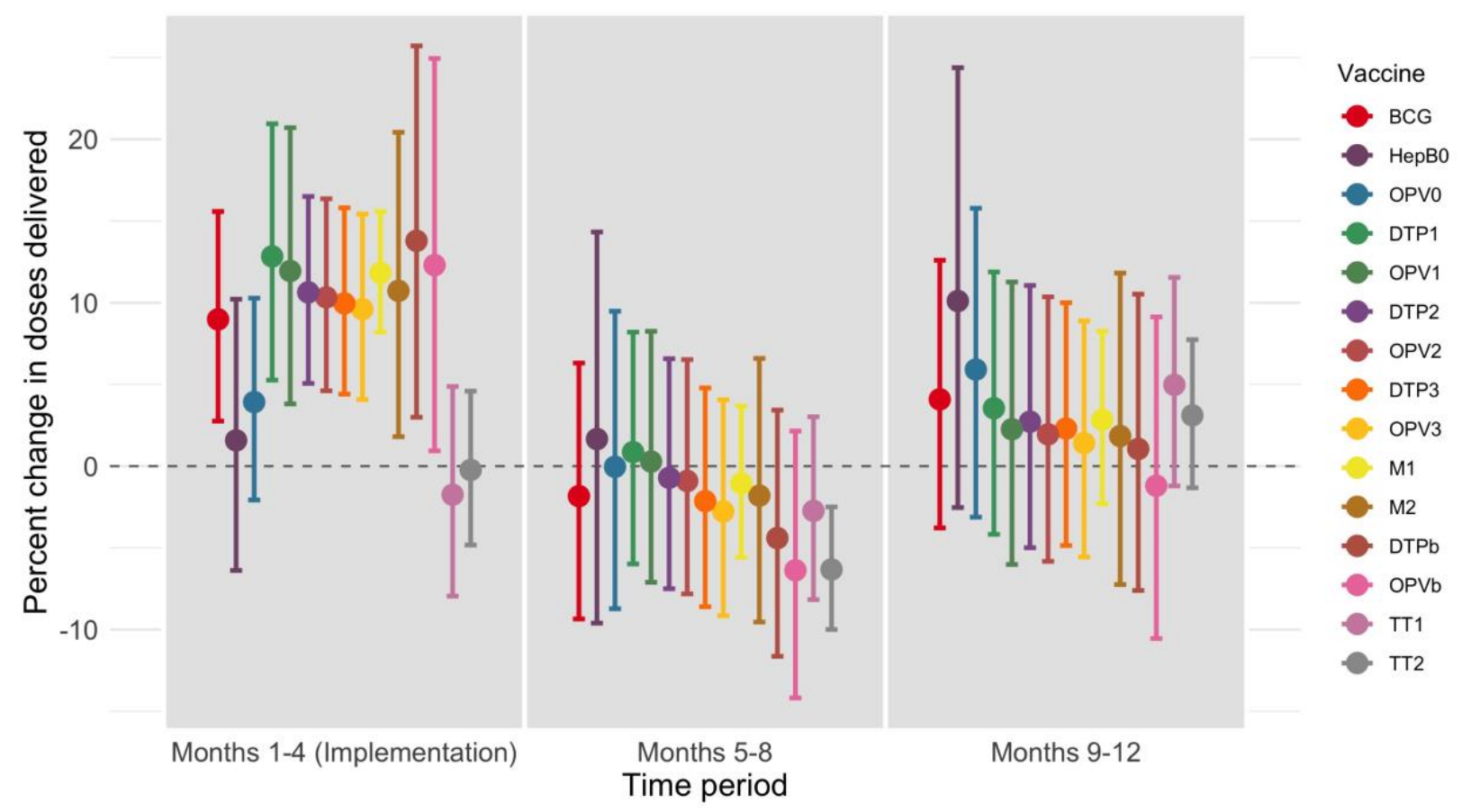

Notes: This figure shows estimates of the effect of IMI on doses delivered, measured as a percent change in doses delivered in each of three time periods ((1) during implementation (Months 1-4); (2) the four months following implementation (Months 5-8); and (3) the four months after that (Months 9-12). Covariate values (urbanization and baseline coverage) are fixed at their mean values. To show percent change, we first exponentiate regression coefficients (because models are fit with a log link function), then subtract one and multiply by 100 . To calculate $95 \%$ confidence intervals on the same scale, we first calculate $95 \%$ confidence intervals on the log scale using assumptions from the normal distribution, and then exponentiate the interval bounds, subtract one, and multiply by 100. 
medRxiv preprint doi: https://doi.org/10.1101/2020.05.01.20087288; this version posted May 6, 2020. The copyright holder for this preprint (which was not certified by peer review) is the author/funder, who has granted medRxiv a license to display the preprint in perpetuity. It is made available under a CC-BY-NC-ND 4.0 International license.

Table 3: Estimated impact of IMI on number of children reached, coverage in the treated districts, and under-coverage in India over one year (October 2017 through September 2018)

\begin{tabular}{|c|c|c|c|}
\hline & $\begin{array}{l}\text { (1) Number of additional } \\
\text { children reached } \\
\text { (thousands) } \\
(95 \% \mathrm{CI})\end{array}$ & $\begin{array}{l}\text { (2) Percentage point } \\
\text { increase in coverage in } \\
\text { treated districts }(95 \% \mathrm{CI})\end{array}$ & $\begin{array}{l}\text { (3) Percentage of } \\
\text { unreached children in the } \\
\text { treated districts reached } \\
\text { through IMI }(95 \% \mathrm{CI})\end{array}$ \\
\hline \multirow[t]{2}{*}{ BCG } & 331 & 3.9 & 31.5 \\
\hline & $(-282 ; 883)$ & $(-3.3,10.4)$ & $(-26.8,83.9)$ \\
\hline \multirow{2}{*}{ HepB0 } & 148 & 1.7 & 3.9 \\
\hline & $(-263,521)$ & $(-3.1,6.1)$ & $(-6.9,13.7)$ \\
\hline \multirow[t]{2}{*}{ OPV0 } & 136 & 1.6 & 5.2 \\
\hline & $(-299,500)$ & $(-3.5,5.9)$ & $(-11.5,19.2)$ \\
\hline \multirow[t]{2}{*}{ DTP1 } & 491 & 5.9 & 35.7 \\
\hline & $(-100 ; 1,033)$ & $(-1.2,12.5)$ & $(-7.5,77.4)$ \\
\hline \multirow{2}{*}{ OPV1 } & 396 & 4.8 & 33.1 \\
\hline & $(-221,969)$ & $(-2.7,11.7)$ & $(-18.5,81.2)$ \\
\hline \multirow[t]{2}{*}{ DTP2 } & 342 & 4.1 & 19.7 \\
\hline & $(-187 ; 832)$ & $(-2.3,10.1)$ & $(-10.7,47.8)$ \\
\hline \multirow[t]{2}{*}{ OPV2 } & 287 & 3.5 & 17.2 \\
\hline & $(-252,823)$ & $(-3.0,9.9)$ & $(-15.1,49.4)$ \\
\hline \multirow[t]{2}{*}{ DTP3 } & 253 & 3.1 & 10.0 \\
\hline & $(-274 ; 733)$ & $(-3.3,8.8)$ & $(-10.9,29.0)$ \\
\hline \multirow[t]{2}{*}{ OPV3 } & 192 & 2.3 & 6.9 \\
\hline & $(-318,670)$ & $(-3.8,8.1)$ & $(-11.5,24.3)$ \\
\hline \multirow[t]{2}{*}{ M1 } & 377 & 4.5 & 16.9 \\
\hline & $(-23 ; 771)$ & $(-0.3,9.3)$ & $(-1.0,34.7)$ \\
\hline \multirow[t]{2}{*}{$\mathrm{DTPb}^{*}$} & 233 & 2.8 & NA \\
\hline & $(-474,857)$ & $(-5.7,10.3)$ & \\
\hline \multirow[t]{2}{*}{ M2* } & 247 & 3.0 & NA \\
\hline & $(-372 ; 793)$ & $(-4.5,9.6)$ & \\
\hline \multirow[t]{2}{*}{$\mathrm{OPVb}^{*}$} & 79 & 1.0 & NA \\
\hline & $(-662,773)$ & $(-8.0,9.3)$ & \\
\hline \multirow[t]{2}{*}{ TT1 } & 6 & 0.1 & 0.7 \\
\hline & $(-393 ; 398)$ & $(-4.6,4.7)$ & $(-47.2,49.9)$ \\
\hline \multirow[t]{2}{*}{ TT2 } & -102 & -1.2 & -6.5 \\
\hline & $(-441 ; 215)$ & $(-5.2,2.5)$ & $(-27.8,13.5)$ \\
\hline
\end{tabular}

Notes: Table shows point estimates and $95 \%$ confidence intervals reflecting estimation uncertainty. Column 1 shows the estimated number of incremental doses delivered due to IMI. This result is calculated by generating predictions from regression models, with covariates set to their true values in the full set of IMI districts. Column 2 shows the estimated percentage point change in coverage in IMI districts. This result is calculated dividing the values in column 1 by an estimate of the target population. The target population is estimated using World Bank data on the population size, birth rate, and neonatal mortality rate in 2017, and HMIS data on the percentage of live births in India that occurred in IMI treatment districts. The full birth cohort is used as the target population for BCG, TT1, and TT2; the birth cohort size less the infant mortality rate is used as the target population for other infant vaccines. Column 3 shows the estimated percentage of unreached children in the treated districts who were reached through IMI. This result is generated by dividing the values in column 1 by an estimate of the number of children in the target districts who would have been unvaccinated if IMI had not occurred. The denominator is calculated by multiplying the rate of under-coverage in 2016 (from DHS estimates) by the size of the target population. NA indicates "Not Applicable." *For these vaccines, there are no estimates of coverage in the 2016 DHS survey. 
Figure 3: Increase in immunization sessions held during IMI implementation

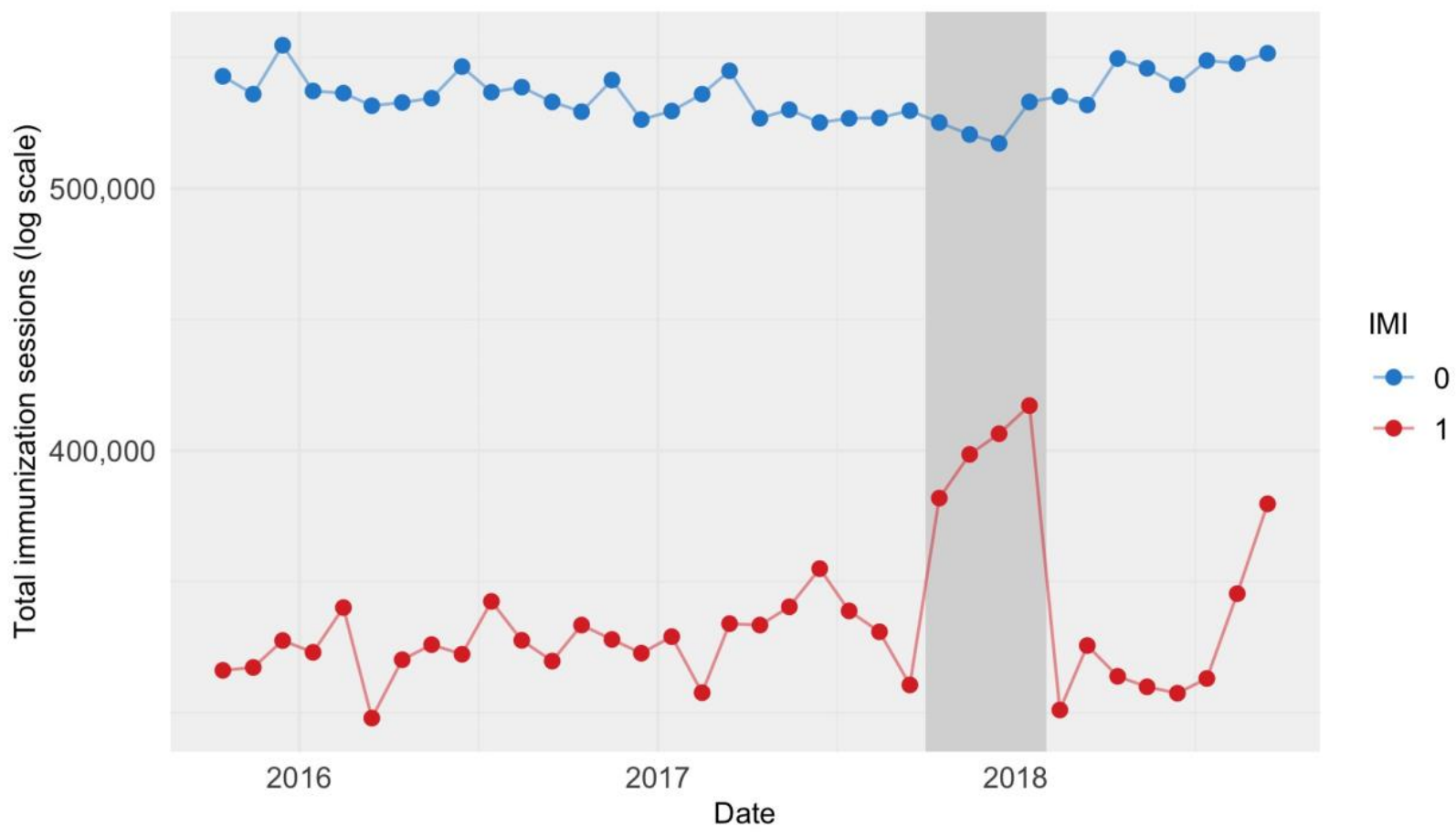

Notes: This figure shows time trends in monthly total immunization sessions held in treated (red) and untreated (blue) districts. The dark gray bar indicates the period of IMI implementation, from October 2017 through January 2018. Raw counts were adjusted for seasonality by subtracting calendar month fixed effects estimated using linear regression models. 
medRxiv preprint doi: https://doi.org/10.1101/2020.05.01.20087288; this version posted May 6, 2020. The copyright holder for this preprint (which was not certified by peer review) is the author/funder, who has granted medRxiv a license to display the preprint in perpetuity.

It is made available under a CC-BY-NC-ND 4.0 International license.

\section{Acknowledgements}

This study was funded by the Bill \& Melinda Gates Foundation. The authors thank participants at the International Heath Economics Association World Congress in July 2019 for their helpful input. 
medRxiv preprint doi: https://doi.org/10.1101/2020.05.01.20087288; this version posted May 6, 2020. The copyright holder for this preprint (which was not certified by peer review) is the author/funder, who has granted medRxiv a license to display the preprint in perpetuity. It is made available under a CC-BY-NC-ND 4.0 International license .

\section{References}

1. WHO. Global vaccine action plan 2011-2020. Geneva: World Health Organization; 2013.

2. WHO/UNICEF estimates of national immunization coverage [Internet]. World Health Organization: Immunization, Vaccines, and Biologicals. [cited 2018 Jan 1]. Available from: http://www.who.int/immunization/monitoring_surveillance/routine/coverage/en/index4.htm 1

3. Arsenault C, Harper S, Nandi A, Mendoza Rodríguez JM, Hansen PM, Johri M. Monitoring equity in vaccination coverage: A systematic analysis of demographic and health surveys from 45 Gavi-supported countries. Vaccine. 2017 Feb;35(6):951-9.

4. Government of India, Ministry of Family Health and Welfare, International Institute for Population Sciences. National Family Health Survey (HFHS-4). Mumbai; 20152016.

5. Oyo-Ita A, Wiysonge CS, Oringanje C, Nwachukwu CE, Oduwole O, Meremikwu MM. Interventions for improving coverage of childhood immunisation in low- and middleincome countries. Cochrane Effective Practice and Organisation of Care Group, editor. Cochrane Database of Systematic Reviews [Internet]. 2016 Jul 10 [cited 2018 Nov 7]; Available from: http://doi.wiley.com/10.1002/14651858.CD008145.pub3

6. Munk C, Portnoy A, Suharlim C, Clarke-Deelder E, Brenzel L, Resch SC, et al. Systematic review of the costs and effectiveness of interventions to increase infant vaccination coverage in low- and middle-income countries. BMC Health Serv Res. 2019 Dec;19(1):741.

7. World Health Organization. Global Routine Immunization Strategies and Practices (GRISP): a companion document to the Global Vaccine Action Plan (GVAP) [Internet]. 2016. Available from: http://apps.who.int/iris/bitstream/10665/204500/1/9789241510103_eng.pdf

8. Periodic Intensification of Routine Immunization: Lessons Learned and Implications for Action [Internet]. John Snow International; 2009. Available from: www.who.int/immunization/programmes_systems/policies_strategies/piri_020909.pdf

9. Shearer FM, Moyes CL, Pigott DM, Brady OJ, Marinho F, Deshpande A, et al. Global yellow fever vaccination coverage from 1970 to 2016: an adjusted retrospective analysis. The Lancet Infectious Diseases. 2017 Nov;17(11):1209-17.

10. Gurnani V, Haldar P, Aggarwal MK, Das MK, Chauhan A, Murray J, et al. Improving vaccination coverage in India: lessons from Intensified Mission Indradhanush, a crosssectoral systems strengthening strategy. BMJ [Internet]. 2018 Dec 7 [cited 2019 Mar 30]; Available from: http://www.bmj.com/lookup/doi/10.1136/bmj.k4782 
medRxiv preprint doi: https://doi.org/10.1101/2020.05.01.20087288; this version posted May 6, 2020. The copyright holder for this preprint (which was not certified by peer review) is the author/funder, who has granted medRxiv a license to display the preprint in perpetuity. It is made available under a CC-BY-NC-ND 4.0 International license .

11. Chatterjee S, Pant M, Haldar P, Aggarwal K, Laxminarayan R. Current costs \& projected financial needs of India's Universal Immunization Programme. The Indian journal of medical research. 2016;143(6):801.

12. Frequently Asked Questions on Immunization (For Health Workers \& Other Front-line Functionaries) [Internet]. Ministry of Health \& Family Welfare, Government of India; 2017. Available from: https://publications.jsi.com/JSIInternet/Inc/Common/_download_pub.cfm?id=19350\&lid=3

13. Francis MR, Nohynek H, Larson H, Balraj V, Mohan VR, Kang G, et al. Factors associated with routine childhood vaccine uptake and reasons for non-vaccination in India: 19982008. Vaccine. 2018 Oct;36(44):6559-66.

14. Laxminarayan R, Ganguly NK. India's Vaccine Deficit: Why More Than Half Of Indian Children Are Not Fully Immunized, And What Can-And Should-Be Done. Health Affairs. 2011 Jun;30(6):1096-103.

15. Vashishtha VM. Status of immunization and need for intensification of routine immunization in India. Indian Pediatrics. 2012 May;49(5):357-61.

16. Intensified Mission Indradhanush: Operational Guidelines [Internet]. Ministry of Health \& Family Wlfare, Government of India; 2017. Available from: https://mohfw.gov.in/sites/default/files/Mission\%20Indradhanush\%20Guidelines.pdf

17. World Bank. World Bank Databank [Internet]. 2017 [cited 2018 Nov 25]. Available from: https://data.worldbank.org/indicator

18. Bernal JL, Cummins S, Gasparrini A. The use of controls in interrupted time series studies of public health interventions. International Journal of Epidemiology. $2018 \mathrm{Dec}$ 1;47(6):2082-93.

19. Jandoc R, Burden AM, Mamdani M, Lévesque LE, Cadarette SM. Interrupted time series analysis in drug utilization research is increasing: systematic review and recommendations. Journal of Clinical Epidemiology. 2015 Aug;68(8):950-6.

20. Novoa AM, Pérez K, Santamariña-Rubio E, Borrell C. Effect on road traffic injuries of criminalizing road traffic offences: a time-series study. Bull World Health Organ. 2011 Jun $1 ; 89(6): 422-31$.

21. Lopez Bernal JA, Gasparrini A, Artundo CM, McKee M. The effect of the late 2000s financial crisis on suicides in Spain: an interrupted time-series analysis. European Journal of Public Health. 2013 Oct;23(5):732-6.

22. Newey WK, West KD. A simple, positive semi-definite, heteroskedasticity and autocorrelation consistent covariance matrix. Econometrica. 1986;55(3):703-8. 
medRxiv preprint doi: https://doi.org/10.1101/2020.05.01.20087288; this version posted May 6, 2020. The copyright holder for this preprint

(which was not certified by peer review) is the author/funder, who has granted medRxiv a license to display the preprint in perpetuity.

It is made available under a CC-BY-NC-ND 4.0 International license.

23. Wagner AK, Soumerai SB, Zhang F, Ross-Degnan D. Segmented regression analysis of interrupted time series studies in medication use research. J Clin Pharm Ther. 2002 Aug;27(4):299-309.

24. Zhang F, Wagner AK, Soumerai SB, Ross-Degnan D. Methods for estimating confidence intervals in interrupted time series analyses of health interventions. Journal of Clinical Epidemiology. 2009 Feb;62(2):143-8.

25. Banerjee AV, Duflo E, Glennerster R, Kothari D. Improving immunisation coverage in rural India: clustered randomised controlled evaluation of immunisation campaigns with and without incentives. BMJ. 2010 May 17;340(may17 1):c2220-c2220.

26. Clark A, Sanderson C. Timing of children's vaccinations in 45 low-income and middleincome countries: an analysis of survey data. The Lancet. 2009 May;373(9674):1543-9. 